\title{
Parameter optimization of the program trajectory of the cellular concrete autoclaving control system
}

\author{
Stanislav Galitskov ${ }^{1}$, Maxim Nazarov ${ }^{1}$, and Andrey Bolkhovetskiy ${ }^{1, *}$ \\ ${ }^{1}$ Samara State Technical University, Institute of Architecture and Civil Engineering, 194, \\ Molodogvardeyskaya St., 443001, Samara, Russia
}

\begin{abstract}
Manufacturing of cellular-concrete products that are widely used in modern construction involves high energy consumption attributable mostly to the process of autoclaving. Insufficient elaboration of issues of mathematical description of autoclaving that would be usable in engineering practice and, consequently, the lack of adequate computational models aimed for practicing technologists, make it necessary to use heuristic approaches to parameter determination for the program trajectories of autoclave automatic control systems (ACS) in manufacturing. Therefore, design and development of autoclaving computational models aimed at parameter optimization of the program trajectory is a very relevant issue. The authors have developed mathematical models of cellular concrete autoclave curing and computational algorithms enabling determination of energy consumption under the variation in dynamic parameters of the automatic system's driver unit. Using the methods of conducting computational experiments under the discrete parameter change of the program trajectory, under the conditions of limitation on the temperature derivative of semi-finished concrete and autoclaving process duration, we have established that completion of the known program trajectory as a polygonal line with two variable slope sections of the third section forming unit with a variable slope, enables reduction of energy consumption up to $8 \%$. The research conducted is specifically focused on the use of the obtained results for optimization of cellular concrete autoclaving ACSs.
\end{abstract}

\section{Introduction}

A significant growth in demand for autoclaved cellular concrete [1-4] paves the way for development of energy-efficient systems and algorithms of control over their manufacturing process. The main process in the production technology [5] of this type of construction materials is autoclaving, i.e. steam treatment of semi-finished cellular concrete mass with a view to obtaining finished products of defined properties. Autoclaving is the most energy-consuming stage in the production of these construction materials. Recognized publications [6-13] describe numerous approaches to adjustment of technological

*Corresponding author: robexa@mail.ru 
parameters for autoclaving of cellular concrete products. However, the lack of mathematical and corresponding computational models results in the use of heuristic approaches to parameter determination for the program trajectories [14] of autoclaving process automatic control systems (ACS) in the construction industry. Modern demands for reduction of energy consumption in the production of construction materials and products necessitate design and development of autoclaving computational models aimed at parameter optimization of the program trajectory based on the criterion of improved energy efficiency of this technological process.

Analysis of algorithms used in practice $[15,16]$ for forming the drive signal in the system for automatic program control of the steam pressure in the autoclave shows that application of such algorithms ensures a predetermined limit of temperature increase rate $d T_{a u t} / d t$ in the autoclave only at the initial stage of pressure rise. The process further continues with a considerably lower $d T_{a u t} / d t$, value, which not only prolongs the autoclaving process, but is also accompanied by relatively high energy consumption.

To achieve the established goal, we therefore find it necessary to change the program trajectory $P_{r}(t)$ of the control system in order to ensure that the limit $d T_{a u t} / d t<d T / d t_{\text {max }}$ is not exceeded throughout the stage of pressure rise. We believe that such control can be implemented if we consider the dynamics of internal heat emission in the autoclaving process, associated with the processes of hydrated calcium silicate formation (primarily tobermorite) in the semi-finished cellular concrete at the temperature rise over $165^{\circ} \mathrm{C}$.

Solution of the set problem requires development of a computational model aimed at research into the influence of parameters of the synthesized program trajectory of the pressure change $P_{\text {aut }}(t)$ in the autoclave on the energy consumption rate, as well as conducting experiments on this model to obtain the results that will help formulate recommendations for their practical application.

\section{Materials and methods}

Mathematical model of energy processes developed by the authors [17] describes, under reasonable assumptions, physical, chemical and thermal processes occurring when autoclaving masses of semi-finished cellular concrete. The model is consistent with the autoclaving regime performed with the pressure $P_{\text {aut }}$ closed system of the program control and temperature $T_{\text {aut }}$ observer in the autoclave (Fig. 1). Besides, the model structure takes into account both internal heat emission during hydrosilicate bond synthesis (section «Heat emission model») described in [17], and the nonlinear nature of the semi-finished product heat capacity.

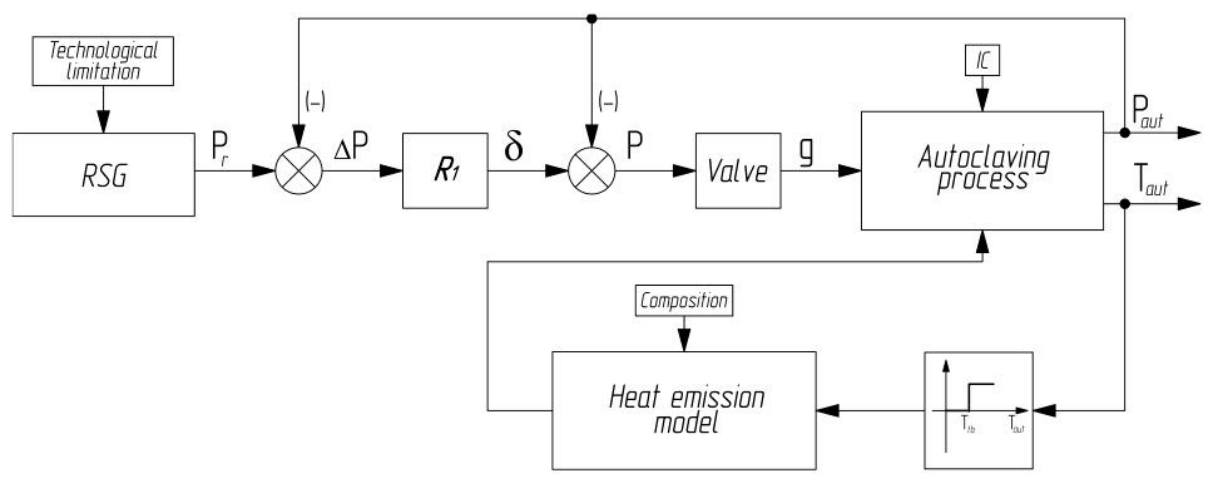

Fig. 1.Structure of the Autoclave Pressure-Closed Control System, where RSG - reference signal generator, $\mathrm{R}_{1}$ - regulator, $\mathrm{IC}$ - initial conditions 
Pressure rise in the autoclave is a two-stage process: initially, the steam is supplied to the autoclave from high and low steam accumulators until the pressure $P_{a c c}=P_{a u t}$ equalizes; at a later stage, direct steam from the boiler is supplied to the autoclave. It is indicative that the temperature change rate $d T_{a u t} / d t$ in the autoclave, according to the data obtained in a commercial plant [15], does not exceed $2^{\circ} \mathrm{C} / \mathrm{min}$. Furthermore, the temperature $T_{\text {aut }}$ and pressure $P_{\text {aut }}$ rise rates at the second stage are limited by the power of steam boilers used in the production of autoclaved cellular concrete.

In contrast to existing models, the suggested program trajectory model of the reference signal generator contains not two (Fig. 2 - I,II), but three (Fig. 2 - III,IV) polygonal line sections with a variable slope. This will improve the control capabilities of the pressure rise dynamics.

Taking into account the existing nonlinearity and nonstationarity of autoclaving energy processes, the research into the influence of the program trajectory parameters on the pressure, temperature and energy consumption dynamics is conducted by the numerical method. For this purpose, on the basis of model [17] and its structural reflection (Fig. 1), a computational model has been developed in the MatLab software environment. Based on this model, a series of experiments was conducted under the variation in the program trajectory parameters. The four most representative examples selected from the numerous results obtained are presented in Table 1.

Table 1. Numerical Values of the Reference Signal Generator Model Component Parameters

\begin{tabular}{|c|c|c|c|c|c|c|c|}
\hline Experiment & $\mathrm{k}_{1} \cdot 10^{-4}$ & $\mathrm{~T}_{1}$ & $\mathrm{k}_{2} \cdot 10^{-4}$ & $\mathrm{~T}_{2}$ & $\mathrm{k}_{2} \cdot 10^{-4}$ & $\mathrm{~T}_{3}$ & $\begin{array}{c}\text { Relative energy } \\
\text { consumption }\end{array}$ \\
\hline I & 5.5 & 6300 & 14.8 & 5400 & - & - & $100 \%$ \\
\hline II & 5.5 & 5400 & 15.7 & 5400 & - & - & $102 \%$ \\
\hline III & 6.9 & 4500 & 14.8 & 1700 & 40 & 1400 & $96 \%$ \\
\hline IV & 5.5 & 5400 & 14.8 & 1700 & 40 & 1400 & $92 \%$ \\
\hline
\end{tabular}

In the experiments, pressure $P_{0}=0.45 \mathrm{MPa}$ produced at the process stage of the vacuum treatment of semi-finished cellular concrete masses loaded in the autoclave is taken as initial condition, while the steady-state value of steam pressure adequate for autoclave curing is $P_{K}=12 M P A$.

A variable slope of polygonal lines $P_{\text {aut }}(t)$ of the reference signal generator is formed parametrically (Table 1). Here, polygonal line I corresponds to the dynamics presented in [15], T1, T2, T3 - temperature values at which slope coefficient values change - k1, k2, k3 for the first, second and third slope sections of the program trajectory respectively.

\section{Results}

As the result of computational experiments conducted on the developed model, it was established that when the suggested parameter adjustment option for the program trajectory of the pressure reference signal generator is used, the temperature change rate in the autoclave (Fig. 3) along the whole section of its pressure rise does not exceed $1.8^{\circ} \mathrm{C} / \mathrm{min}$, which does not contradict the data presented in [15]. 


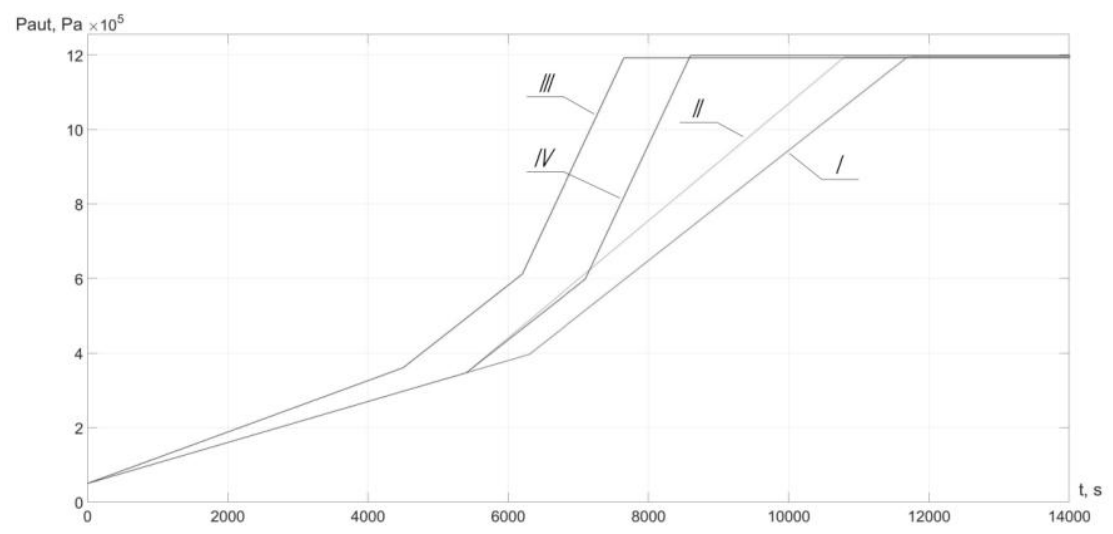

Fig. 2.Program Trajectories of the Reference Signal Generator by the Parameters of Experiments I-IV

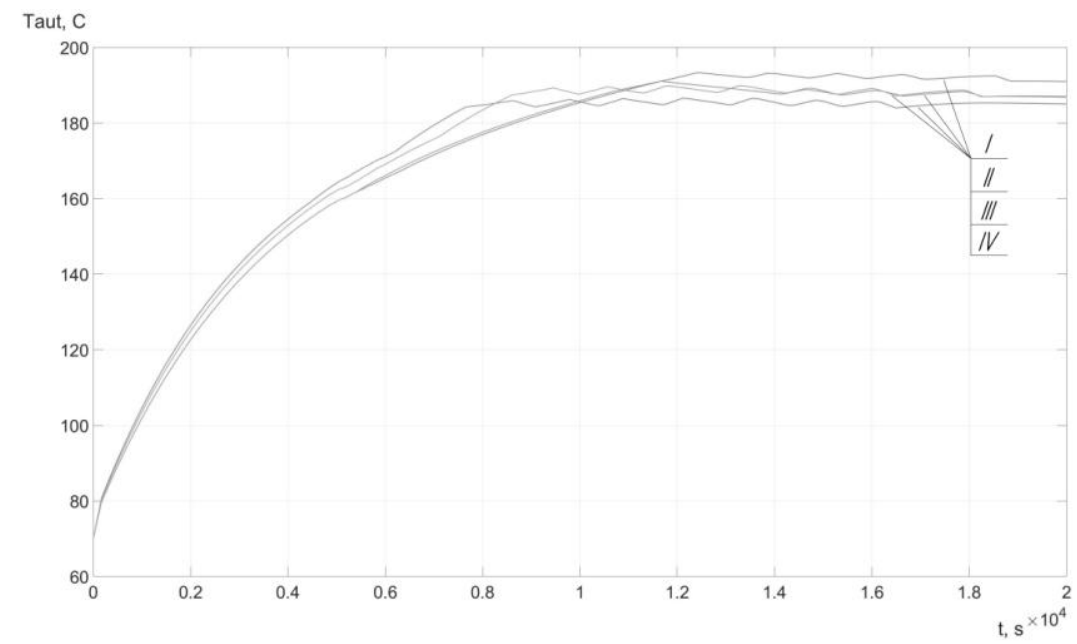

Fig. 3.Temperature in the Autoclave in Experiments I-IV (Table 1)

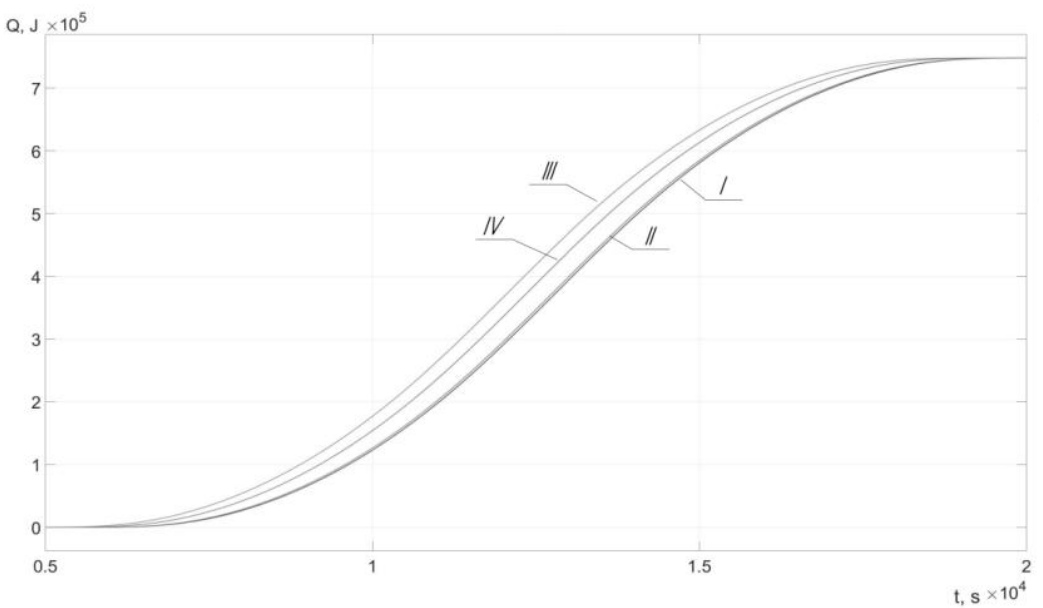

Fig. 4.Energy of Internal Heat Emission During Tobermorite Formation $Q_{t b}$ 


\section{Discussion}

It is shown that the formed dynamics change of the temperature in the autoclave shifts the start time of internal heat emission during hydrated calcium silicate formation to the left (Fig. 4), which enables making maximum use of the additional energy released in the course of cellular concrete hardening.It is established that the designed parameter optimization of the program trajectory enables reduction of energy consumption in the process of autoclave curing of cellular concrete products up to the value of $8 \%$.

\section{Conclusions}

Computational experiments have been conducted and results have been obtained that show the efficiency of parameter optimization of the program trajectory for the purposes of reducing energy consumption in the production of cellular concrete products.

\section{References}

1. V.A.Shamanov, S.V.Leontyev, A.D.Kurzanov, V.A.Golubev, V.A.Kharitonov, Fundamental research,5,558-563 (2015).

2. A.A. Vishnevsky, G.I. Greenfield, N.O.Kulikova, Construction materials,7, 40-44 (2013).

3. G.I. Greenfield, Concrete technologies,7-8, 12-14 (2011).

4. V.Y. Klyuev, Scientific research,2(6),58-63 (2008).

5. A.V. Vysochkin, Materials of the 7th International Scientific and Practical Conference, 83-84 (2012).

6. T.V. Sazonova, A.A. Khodakov, Proceedings book of the 2nd All-Russian scientific and practical conference with international participation,47-53 (2011).

7. A.S. Semchenkov, T.A. Ukhova, G.P. Sakharov, Construction materials,6, 4-7 (2006).

8. M.V. Kaftayeva, I.S. Rakhimbayev, Applied and Fundamental Research,10, 266269(2013).

9. N.P. Sazhnev, Materials of the 7th International Scientific and Practical Conference, 5-16 (2012).

10. D.G. Rudchenko, Experience of Production and Application of Autoclave Hardened Cellular Concrete: materials of the 7th International Scientific and Practical Conference (2012).

11. D.G. Rudchenko, Experience of Production and Application of Autoclave Hardened Cellular Concrete: materials of the 8th International Scientific and Practical Conference, 49-54 (2014).

12. L.V. Akatyeva, PhD Thesis(Moscow, 2003).

13. A.N. Kuznetsov,Proceedings book of scientific and practical conference «Modern Production of Autoclaved Gas Concrete», 33-39 (2011).

14. M.V. Kaftayeva, O.N. Sharapov, M.A. Shugayeva, I.S. Rakhimbayev, Current Issues of Science and Education,6, 1-6 (2013).

15. M.V. Kaftayeva, I.S. Rakhimbayev, International journal of applied and fundamental research,10, 373-376 (2013).

16. V.A.Danilushkin, P.I. Ruban, A.Yu. Taymolkin, Urban Construction and Architecture,2, 128-131 (2011). doi: 10.17673/Vestnik.2011.02.28. 
17. S.Y. Galitskov, V.N. Mikhelkevich, A.S. Bolkhovetsky, Materials of the 8th International Conference «Problems of Management and Control in Complex Systems», 347-350 (2016). 